\title{
BUKU PEMBELAJARAN BAHASA INGGRIS DENGAN TEKNOLOGI AUGMENTED REALITY BERBASIS ANDROID
}

\author{
Quraish $^{1)}$, Rinta Kridalukmana ${ }^{2)}$, Kurniawan Teguh Martono ${ }^{3)}$ \\ Program Studi Sistem Komputer, Fakultas Teknik, Universitas Diponegoro \\ Jalan Prof. Sudharto, Tembalang, Semarang, Indonesia
}

\begin{abstract}
Abstrak - Buku adalah media yang paling sederhana untuk memperoleh dan memberikan informasi, Augmented Reality dapat digunakan untuk menampilkan multimedia dengan cara menambahkannya pada dunia nyata, dengan penggabungan buku dalam hal ini bahasa inggris dan augmented reality maka multimedia dapat ditampilkan dan dapat digunakan sebagai media pembelajaran yang interaktif.
\end{abstract}

Untuk membangun aplikasi dalam hal ini augmented reality dibutuhkan suatu metode, metode yang digunakan untuk membangun aplikasi augmented reality ini adalah SDLC (Software Defelopment Life Cycle) yang menggunakan teknik waterfall, hal ini dipilih karena waterfall lebih terurut dalam membangun aplikasi.

Augmented Reality yang dibangun memiliki keberhasilan deteksi yang berbeda-beda, jarak yang dapat dipakai dalam mendeteksi penanda adalah mulai dari jarak $15 \mathrm{~cm}$ sampai $60 \mathrm{~cm}$ dan semakin besar tingkat kemiringan penanda terhadap kamera maka semakin sulit penanda terdeteksi, semakin besar persentase penanda terhalang maka semakin besar juga kemungkinan penanda sulit terdeteksi.

Kata Kunci : Augmented Reality, Multimedia, Buku Bahasa Inggris, SDLC.

\section{Pendahuluan}

\subsection{Latar Belakang}

Buku adalah media yang paling sederhana untuk dapat memperoleh dan memberikan informasi yang dibutuhkan serta mendapatkan pengetahuan. Jenis buku sangat beragam baik ukuran maupun isi, misalnya ensiklopedia, majalah, komik, dan lain-lain. Buku merupakan salah satu kebutuhan manusia yang penting. Manfaat buku selain sebagai jendela dunia dimana masyarakat dapat mendapatkan informasi, juga sebagai sarana rekreasi bagi mereka yang gemar membaca. Dengan kata lain buku memiliki peran besar bagi masyarakat $^{[1]}$.

Multimedia merupakan salah satu sarana yang sering digunakan pada berbagai bidang, baik itu hiburan, pendidikan, bisnis, serta berbagai kepentingan lainnya. Multimedia adalah suatu teknologi yang menggabungkan berbagai sumber media seperti teks, grafik, suara, animasi, video dan sebagainya yang disampaikan dan dikontrol oleh sistem komputer secara interaktif ${ }^{[6]}$.

Berdasarkan hal tersebut, munculah ide untuk mengembangkan buku pembelajaran yang lebih interaktif yang menggunakan multimedia sebagai salah satu cara untuk menikmati proses belajar dengan menggunakan nuansa baru yaitu teknologi Augmented Reality. Augmented Reality merupakan salah satu teknologi yang digunakan untuk menggabungkan antara dunia maya dengan dunia nyata ${ }^{[2]}$.

1.2 Pembatasan Masalah

Untuk menghindari pembahasan yang meluas maka dalam tugas akhir ini ditetapkan batasan-batasan masalah dengan hal-hal sebagai berikut:

a. Lingkup kerja pembuatan tugas akhir adalah pada Pembuatan buku dan aplikasi augmented reality serta animasi 3D, video dan beberapa gambar 3D, namun lebih berfokus pada pembuatan aplikasi augmented reality.

b. Aplikasi hanya berjalan pada smartphone dengan operating system Android dengan minimum Android 2.3 (Gingerbread).

c. Aplikasi menggunakan teknologi augmented reality dengan Unity sebagai komponen pembuatnya, serta vuforia sebagai software development kit-nya.

1.3 Tujuan

Tujuan dilakukannya penelitian dalam tugas akhir ini adalah menciptakan sebuah buku pembelajaran bahasa inggris dengan menggunakan teknologi augmented reality berbasis android yang dapat digunakan sebagai media pembelajaran yang interaktif serta memberikan nuansa baru (Augmented Reality) dalam belajar kosa kata bahasa inggris. 


\section{LANDASAN TEORI}

\subsection{Multimedia}

Multimedia berasal dari kata multi yang berarti banyak atau lebih dari satu media antara lain berupa gambar, tulisan (text), foto, video dan audio. Multi dalam bahasa Latin berarti banyak atau berbagai, medium di dalam bahasa Latin berarti perantara atau suatu perantara yang digunakan untuk menghantar atau menyampaikan sesuatu seperti komunikasi massa seperti surat kabar, majalah atau televisi ${ }^{[8]}$.

Definisi lain dari multimedia adalah suatu teknologi yang menggabungkan berbagai sumber media seperti teks, grafik, suara, animasi, video dan sebagainya yang disampaikan dan dikontrol oleh sistem komputer secara interaktif ${ }^{[6]}$.

Multimedia terbagi menjadi beberapa komponen, antara lain :

\section{Audio / Suara}

Audio atau suara didalam multimedia biasanya berupa suara musik, suara dari voice record dan efek-efek suara lain. Beberapa format audio yang digunakan dalam multimedia yaitu MP3, WAV, DAT.

\section{Video}

Video adalah bagian dari gambar-gambar yang saling berurutan yang disebut frame dengan standar 24 frame/second $($ FPS = Frame Per Second), gambar-gambar tersebut kemudian diproyeksikan diatas layar ditambah dengan objek teks atau animasi.

\section{Gambar / Image}

Gambar merupakan tampilan diam atau tidak bergerak, gambar juga merupakan salah satu komponen penting dalam multimedia karena dapat meringkas dan menyajikan data kompleks, gambar dalam publikasi multimedia lebih menarik perhatian dan dapat mengurangi kebosanan dibandingkan dengan teks sebab manusia selalu berorientasi terhadap visual (berdasarkan penglihatan).

\section{Teks}

Teks adalah elemen paling awal dan sederhana dalam multimedia, yang biasanya mengacu pada kata, kalimat, alinea, atau segala sesuatu yang tertulis atau ditayangkan. Sebagian besar multimedia menggunakan teks karena teks sangat efektif untuk menyampaikan ide dan panduan kepada pengguna. Teks merupakan bentuk data multimedia yang paling mudah disimpan dan dikenali, serta file teks mempunyai struktur yang sederhana.

5. Animasi

Animasi merupakan kumpulan gambar yang ditampilkan secara bergantian dan berurutan sehingga terlihat bergerak dan hidup. Pergerakan animasi akan lebih mudah dimengerti daripada objek atau gambar diam. Selain itu animasi lebih menarik dan mudah dimengerti daripada hanya sekedar gambar karena lebih komunikatif dalam menyampaikan suatu tujuan. ${ }^{[8]}$

\subsection{Augmented Reality}

Augmented Reality merupakan salah satu teknologi yang digunakan untuk menggabungkan antara dunia maya dengan dunia nyata ${ }^{[2]}$, dunia maya yang dimaksud dapat beraneka macam seperti : gambar 3 dimensi, animasi 3 dimensi, video ataupun suara yang semuanya dapat dipadukan dengan lingkungan sebenarnya sehingga pengguna dapat merasakan objek berada dalam lingkungannya.

Cara kerja Augmented Reality dalam menambahkan objek ke lingkungan nyata adalah sebagai berikut : ${ }^{[3]}$

1. Perangkat input menangkap gambar (penanda) dan mengirimkannya ke prosesor.

2. Perangkat lunak di dalam prosesor mengolah gambar dan mencari suatu pola.

3. Perangkat lunak menghitung posisi pola untuk mengetahui dimana objek virtual akan diletakan.

4. Perangkat lunak mengidentifikasi pola dan mencocokkannya dengan informasi yang dimiliki perangkat lunak.

Berdasarkan teknik pendeteksian objek (objecttracking techniques) sistem augmented dibagi menjadi 3 jenis, yaitu positioning, marker, dan markerless augmented reality services. Jenis sistem sistem augmented reality positioning cukup sederhana dalam penggunaannya. Sistem ini menggunakan posisi sebagai penanda, sehingga biasa dipadukan dengan GPS pada ponsel cerdas. Jenis sistem augmented reality marker menggunakan teknik untuk mendeteksi penanda (marker) yang sudah diprogram sebelumnya untuk dikenali. Sebuah marker biasanya berupa persegi dengan warna latar putih dan dengan beberapa corak hitam. Kedua warna ini lebih sering digunakan karena pengaruh sensitivitas cahaya terhadap warna hitam dan putih sehingga mudah untuk dideteksi. Marker jenis ini biasa disebut sebagai marker statis. Namun terdapat marker yang berbentuk abstrak. Marker jenis tersebut sering juga dikategorikan sebagai markerless yang berupa pola kompleks yang terdiri dari tulisan, gambar, atau warna ${ }^{[9]}$.

\subsection{Android}

Android adalah sistem operasi berbasis Linux yang dirancang untuk perangkat seluler layar sentuh seperti telepon pintar dan komputer tablet. Android awalnya dikembangkan oleh Android, Inc., dengan dukungan finansial dari Google, yang kemudian membelinya pada tahun 2005. Sistem operasi ini dirilis secara resmi pada tahun 2007, bersamaan dengan didirikannya Open Handset Alliance, konsorsium dari perusahaanperusahaan perangkat keras, perangkat lunak, dan telekomunikasi yang bertujuan untuk memajukan standar terbuka perangkat seluler. Ponsel Android pertama mulai dijual pada bulan Oktober 2008. ${ }^{[7]}$

\subsection{Unity 3D}

Unity adalah salah satu game engine yang banyak digunakan. Dengan software ini, membuat game sendiri dapat dilakukan dengan lebih mudah dan cepat. Hebatnya lagi, unity mensuport pembuatan game dalam berbagai platform, misal Unity Web, Windows, Mac, Android, iOS, XBox, Playstation 3 dan Wii. ${ }^{[5]}$

\subsection{Vuforia}

Vuforia merupakan Augmented Reality Software Development Kit, yang merupakan perlengkapan penunjang Augmented Reality yang diperlukan sebagai tambahan suatu application development agar memungkinkan menggunakan Augmented Reality. 
Vuforia SDK bisa didapatkan secara bebas melalui website resmi vuforia dan dapat dipilih sesuai kebutuhan aplikasi yang akan digunakan untuk membangunnya, diantaranya adalah Unity Extension, iOS atau Android. vuforia dikembangkan oleh Qualcomm, diskusi mengenai pengembangan vuforia dapat ditemui pada forum vuforia serta komunitas aktif yang mengembangkannya. Pada pengembangan aplikasi augmented reality markerless Vuforia dapat dimanfaatkan dengan mudah dengan menggunakan fitur-fitur yang terdapat didalamnya, diantaranya adalah ImageTarget, serta AR camera yang merupakan fitur dasar pengembangan aplikasi augmented reality markerless ${ }^{[9]}$.

\section{ANALISIS DAN PERANCANGan Sistem}

System Development Life Cycle (SDLC) merupakan metode pengembangan sistem yang umum digunakan ${ }^{[4]}$. Salah satu teknik pengembangan SDLC adalah teknik waterfall. Teknik ini melakukan pendekatan secara sistematis dan urut mulai dari tahap analisis, desain, implementasi, pengujian, dan maintenance. Disebut dengan waterfall karena tahap demi tahap yang dilalui harus menunggu selesainya tahap sebelumnya dan berjalan berurutan, Mempertimbangkan prosesnya yang urut, teratur dan menjadikan jadwal lebih menentu ${ }^{[4]}$. Aplikasi buku bahasa inggris dengan augmented reality ini dikembangkan menggunakan metode SDLC waterfall namun hanya sampai pada tahapan pengujian dan tidak sampai pada tahapan maintenance karena pada tugas akhir ini tidak mencapai proses pendistribusian.

\subsection{Analisis Kebutuhan dan Sistem}

Kebutuhan fungsional merupakan kebutuhan dari sistem yang memiliki kegunaan secara dasar agar aplikasi dapat berjalan sesuai dengan tujuan pembuatannya. Pada aplikasi buku bahasa inggris terdapat beberapa kebutuhan fungsional, antara lain yaitu:

1. Menu utama aplikasi serta tombol yang terdapat didalamnya dapat diakses dengan benar dan sesuai.

2. Kamera pada perangkat bergerak dapat menangkap gambar penanda pada buku bahasa inggris.

3. Aplikasi dapat menampilkan gambar 3D, animasi 3D, video atau suara saat kamera menangkap gambar penanda yang terdapat pada buku.

Kebutuhan non fungsional merupakan kebutuhan tambahan yang berfungsi dalam menambah sisi menarik aplikasi ataupun sekedar memberikan tambahantambahan tertentu dalam pengembangan aplikasi tersebut agar bisa berjalan. Beberapa kebutuhan non fungsional pada aplikasi buku bahasa inggris ini adalah:

1. Desain penanda / marker berpengaruh pada sistem sehingga masing-masing desain penanda harus dibuat agar dapat terdeteksi dan harus dibuat berbeda satu sama lain.

2. Desain gambar 3D, animasi 3D dan video.

3. Aplikasi dibuat pada perangkat bergerak untuk sistem operasi android.

4. Pembagian halaman utama menjadi 4 bagian yaitu gambar 3D, video, animasi 3D angka dan animasi
3D warna berfungsi agar waktu respon dari halaman menu ke halaman utama lebih cepat.

5. Penambahan tombol putar (untuk memutar objek 3D) dan scrollbar perbesar objek (untuk memperbesar objek 3D).

\subsection{Diagram Alir}

Pada perancangan sistem aplikasi ini, dibuat diagram alir untuk menunjukan proses kerja aplikasi. Gambar 2 menunjukkan diagram alir program secara keseluruhan.

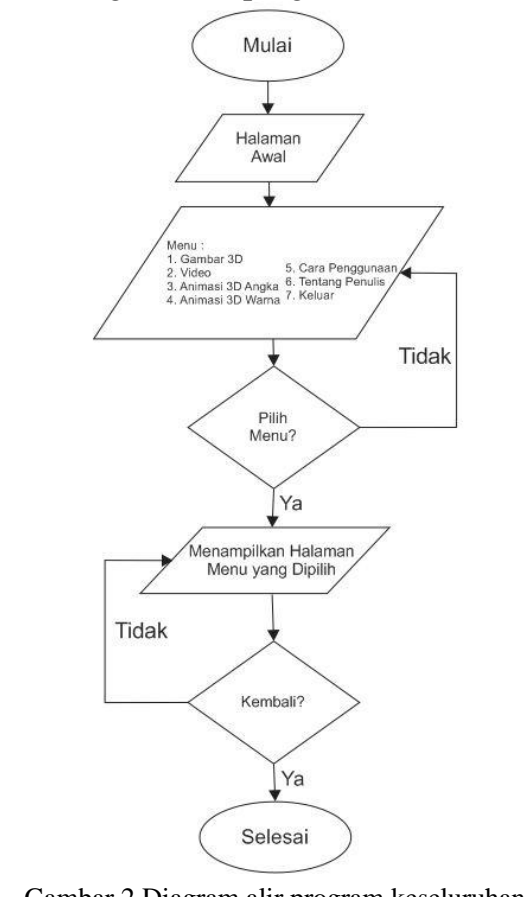

\subsection{Perancangan Antarmuka}

Terdapat beberapa perancangan antarmuka pada aplikasi ini. Diantaranya yaitu tampilan halaman gambar 3D yang ditunjukkan oleh gambar 3, tampilan halaman video yang ditunjukkan oleh gambar 4, tampilan halaman animasi 3D angka yang ditunjukkan oleh gambar 5 dan tampilan halaman animasi 3D warna yang ditunjukkan oleh gambar 6 .

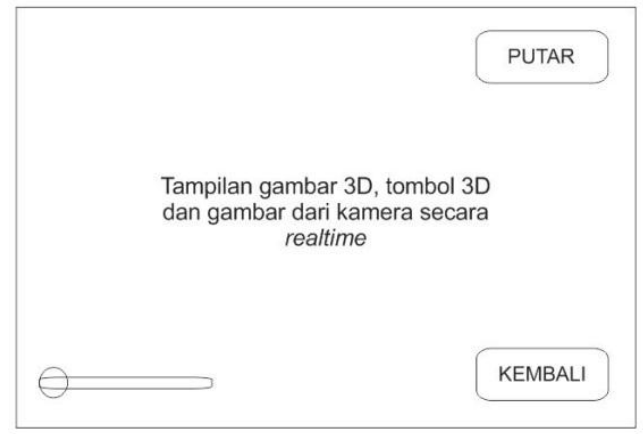

Gambar 3 Perancangan antarmuka halaman gambar 3D 


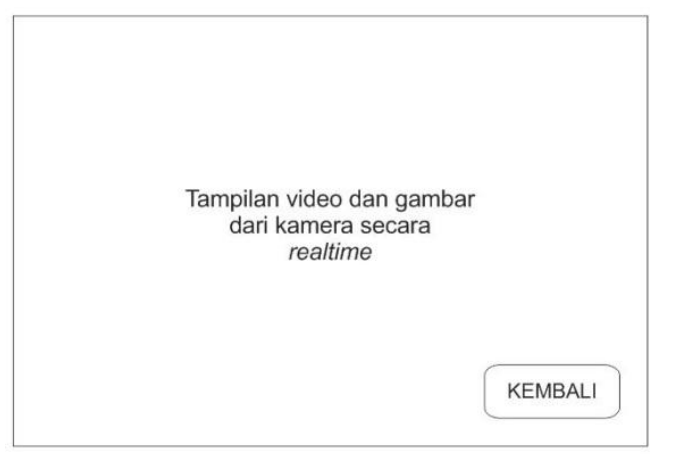

Gambar 4 Perancangan antarmuka halaman video

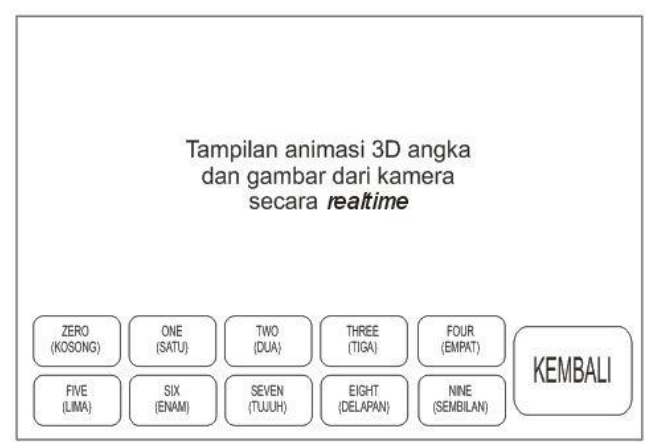

Gambar 5 Perancangan antarmuka halaman animasi 3D angka

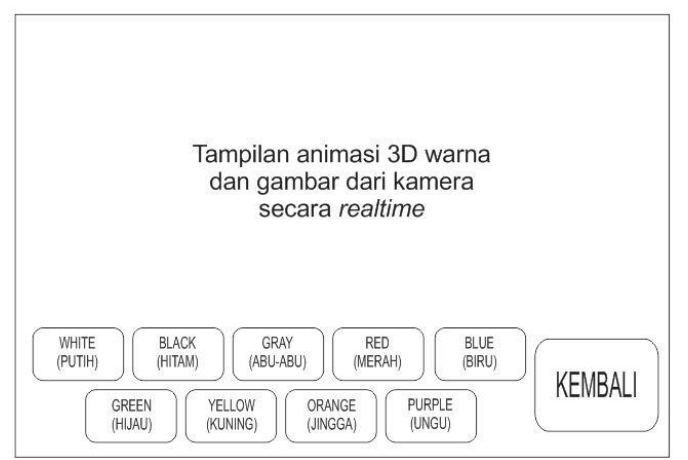

Gambar 6 Perancangan antarmuka halaman animasi 3D warna

\subsection{Pemodelan Perangkat Lunak}

Pemodelan perangkat lunak yang digunakan adalah use case, Diagram use case digunakan untuk menjelaskan apa saja yang dapat dilakukan oleh sistem terhadap pengguna secara keseluruhan termasuk diantaranya fungsi-fungsi tambahan dalam aplikasi, diagram use case ditunjukkan oleh gambar 7 .

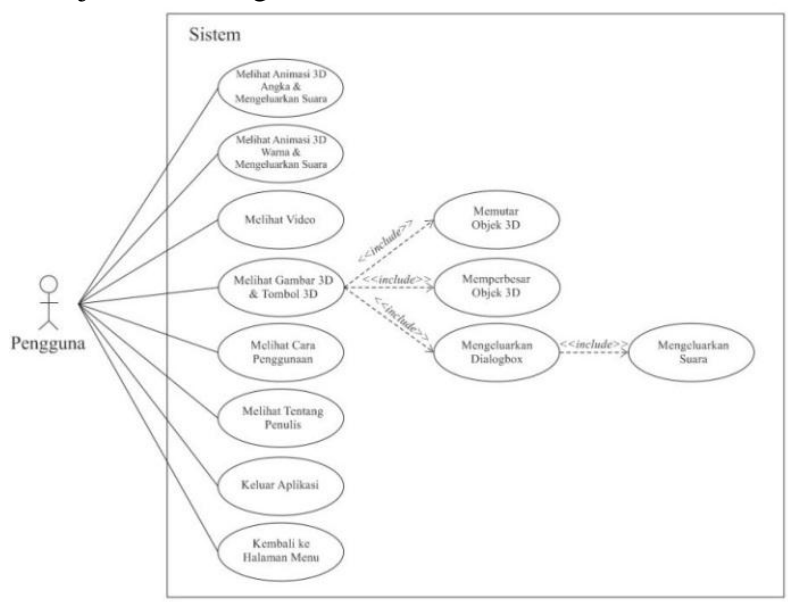

Gambar 7 Diagram use case

\section{IMPLEMENTASI DAN PENGUJIAN}

\subsection{Implementasi}

Tahapan implementasi merupakan tahapan dimana dilakukan penulisan kode program dan menggabungkannya dengan perancangan antarmuka sesuai dengan yang sudah dirancang pada tahapan perancangan. Adapun implementasi sistem yang dilakukan antara lain sebagai berikut.

1. Memasukan Pustaka Vuforia pada Unity.

Tahapan ini merupakan tahapan awal implementasi sistem, yang mana pada pengembangan aplikasi buku bahasa inggris ini digunakan Unity sebagai software pengembangannya, dan Software Development Kit yang digunakan adalah Vuforia. Oleh karena itu, pustaka dari Vuforia diperlukan untuk di-Load pada Unity yang akan digunakan tersebut. Pustaka Vuforia Unity dapat diunduh di situs https://developer.vuforia.com/ yang merupakan situs resmi Vuforia Qualcomm. Setelah mengunduh, untuk meggunakannya bisa dilakukan pada Unity dengan menekan menu Assets $\rightarrow$ Import $\rightarrow$ Custom Package. Gambar 8 menunjukkan package vuforia yang diimpor ke dalam unity.

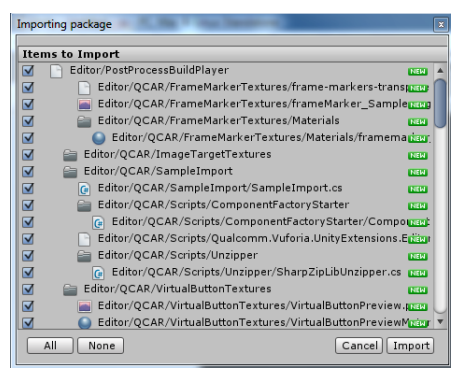

Gambar 8 Package Vuforia yang di import ke dalam Unity.

\section{Implementasi Halaman Aplikasi}

Halaman aplikasi yang dibuat adalah halaman awal aplikasi, halaman menu, halaman gambar 3D, halaman video, halaman animasi 3D angka, halaman 3D warna, halaman cara penggunaan, halaman tentang penulis dan halaman keluar. Yang mana halaman- halaman ini ditunjukkan oleh gambar 9 sampai gambar 17.

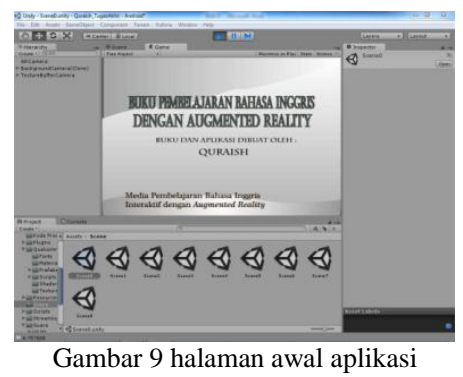




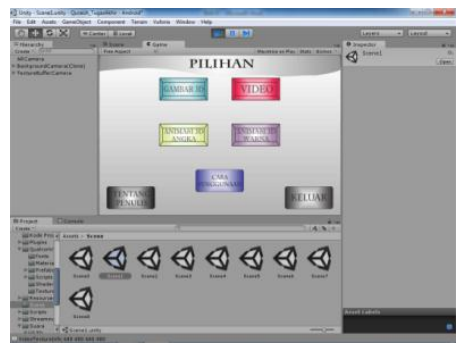

Gambar 10 halaman menu

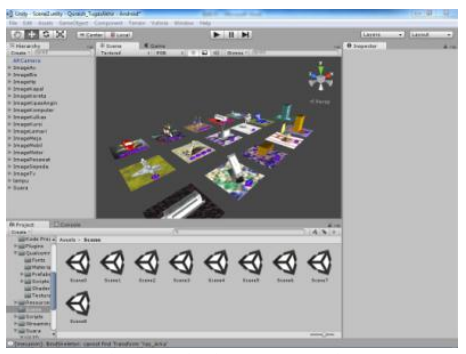

Gambar 11 halaman gambar 3D

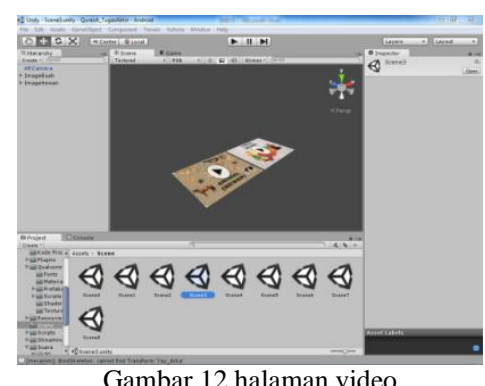

Gambar 12 halaman video

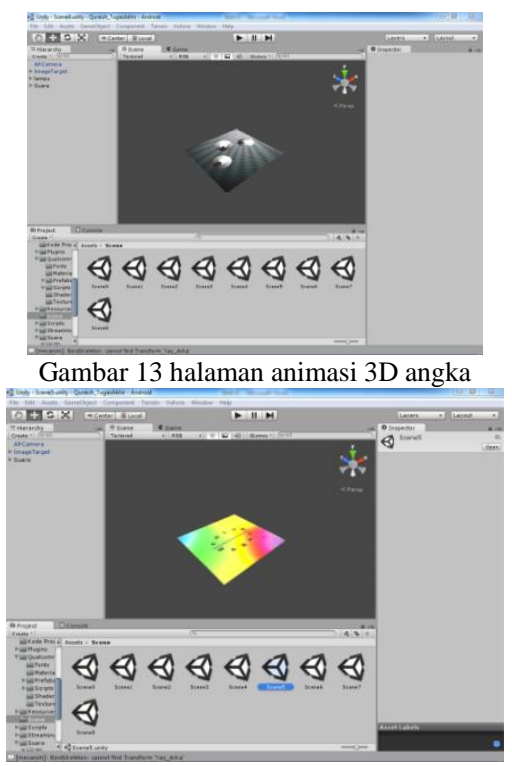

Gambar 14 halaman animasi 3D warna

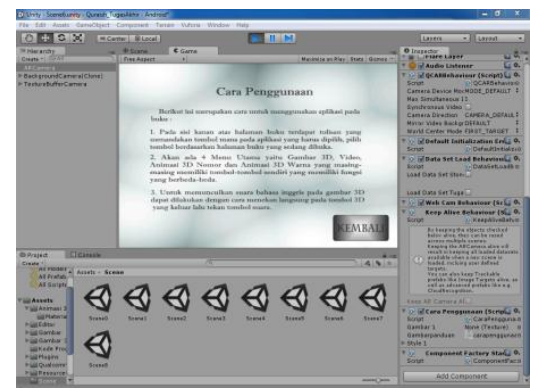

Gambar 15 halaman cara penggunaan

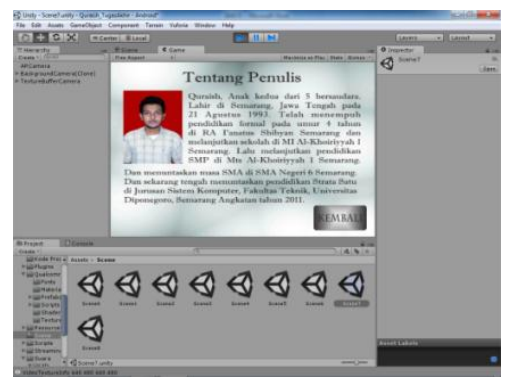

Gambar 16 halaman tentang penulis

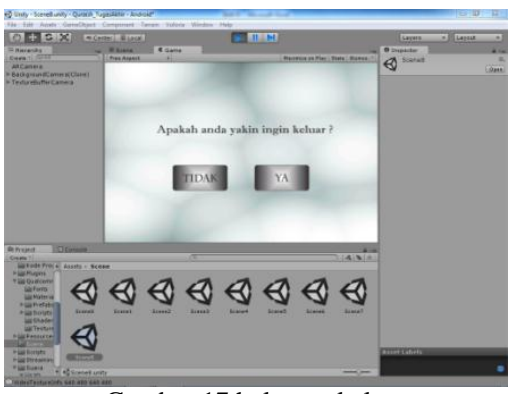

Gambar 17 halaman keluar

\subsection{Pengujian Aplikasi}

Pengujian pada tahap ini bermaksud untuk menguji aplikasi serta memastikan aplikasi dapat berjalan seperti tujuan dan seluruh fungsi dapat digunakan. Pengujian yang dilakukan menggunakan metode black-box. Pengujian black-box merupakan pengujian yang lebih berfokus pada sisi fungsionalitas aplikasi dan tingkat keberhasilan pengujian diukur dari terpenuhinya tujuan dari fungsi yang sudah dibuat.

\section{Pengujian Fungsi}

Pengujian aplikasi ini dibuat berupa tabel pengujian black-box dari fungsi yang ada dalam aplikasi. Tabel 1 menunjukkan hasil pengujian fungsi-fungsi yang terdapat pada aplikasi .

Tabel 1. Pengujian fungsi

\begin{tabular}{|c|l|l|l|c|}
\hline No & \multicolumn{1}{|c|}{$\begin{array}{l}\text { Fungsi yang } \\
\text { diuji }\end{array}$} & Kondisi Awal & $\begin{array}{l}\text { Kondisi Akhir yang } \\
\text { diharapkan }\end{array}$ & Hasil \\
\hline 1. & $\begin{array}{l}\text { Membuka } \\
\text { aplikasi }\end{array}$ & $\begin{array}{l}\text { Pengguna belum } \\
\text { membuka } \\
\text { aplikasi }\end{array}$ & $\begin{array}{l}\text { Sistem } \\
\text { menampilkan anal } \\
\text { halaman } \\
\text { aplikasi. }\end{array}$ & Berhasil \\
\hline 2. & $\begin{array}{l}\text { Membuka } \\
\text { halaman menu }\end{array}$ & $\begin{array}{l}\text { Pengguna telah } \\
\text { melewati } \\
\text { halaman awal }\end{array}$ & $\begin{array}{l}\text { Sistem } \\
\text { menampilkan menu } \\
\text { halaman } \\
\text { aplikasi }\end{array}$ & Berhasil \\
\hline 3. & $\begin{array}{l}\text { Melihat } \\
\text { halaman } \\
\text { gambar 3D }\end{array}$ & $\begin{array}{l}\text { Pengguna pada } \\
\text { berada palaman menu } \\
\text { halanam }\end{array}$ & $\begin{array}{l}\text { Sistem } \\
\text { halaman gambar 3D, }\end{array}$ & Berhasil \\
\hline
\end{tabular}




\begin{tabular}{|c|c|c|c|c|}
\hline & & & $\begin{array}{l}\text { dan mengaktifkan } \\
\text { kamera untuk } \\
\text { menerapkan } \\
\text { teknologi } \\
\text { augmented reality. }\end{array}$ & \\
\hline 4. & $\begin{array}{l}\text { Melihat } \\
\text { halaman video }\end{array}$ & $\begin{array}{l}\text { Pengguna } \\
\text { berada pada } \\
\text { halaman menu }\end{array}$ & $\begin{array}{l}\text { Sistem } \\
\text { menampilkan } \\
\text { halaman video dan } \\
\text { mengaktifkan } \\
\text { kamera untuk } \\
\text { menerapkan } \\
\text { teknologi } \\
\text { augmented reality. }\end{array}$ & Berhasil \\
\hline 5. & $\begin{array}{l}\text { Melihat } \\
\text { halaman } \\
\text { animasi } \\
\text { angka }\end{array}$ & $\begin{array}{l}\text { Pengguna } \\
\text { berada pada } \\
\text { halaman menu }\end{array}$ & $\begin{array}{l}\text { Sistem } \\
\text { menampilkan } \\
\text { halaman animasi 3D } \\
\text { angka dan } \\
\text { mengaktifkan } \\
\text { kamera untuk } \\
\text { menerapkan } \\
\text { teknologi } \\
\text { augmented reality. }\end{array}$ & Berhasil \\
\hline 6. & $\begin{array}{l}\text { Melihat } \\
\text { halaman } \\
\text { animasi } \\
\text { warna }\end{array}$ & $\begin{array}{l}\text { Pengguna } \\
\text { berada pada } \\
\text { halaman menu }\end{array}$ & $\begin{array}{l}\text { Sistem } \\
\text { menampilkan } \\
\text { halaman animasi 3D } \\
\text { warna dan } \\
\text { mengaktifkan } \\
\text { kamera untuk } \\
\text { menerapkan } \\
\text { teknologi } \\
\text { augmented reality. }\end{array}$ & Berhasil \\
\hline 7. & $\begin{array}{l}\text { Melihat } \\
\text { halaman cara } \\
\text { penggunaan }\end{array}$ & $\begin{array}{l}\text { Pengguna } \\
\text { berada pada } \\
\text { halaman menu }\end{array}$ & $\begin{array}{l}\text { Sistem } \\
\text { menampilkan } \\
\text { halaman } \\
\text { penggunaan. }\end{array}$ & Berhasil \\
\hline 8. & $\begin{array}{l}\text { Melihat } \\
\text { halaman tentang } \\
\text { penulis }\end{array}$ & $\begin{array}{l}\text { Pengguna } \\
\text { berada pada } \\
\text { halaman menu }\end{array}$ & $\begin{array}{l}\text { Sistem } \\
\text { menampilkan } \\
\text { halaman tentang } \\
\text { penulis }\end{array}$ & Berhasil \\
\hline 9. & Fungsi kembali & $\begin{array}{lr}\text { Pengguna } & \\
\text { berada } & \text { pada } \\
\text { halaman yang } \\
\text { terdapat } & \text { tombol } \\
\text { kembali. } & \\
\end{array}$ & $\begin{array}{ll}\text { Sistem } & \text { akan } \\
\text { menampilkan } & \\
\text { halaman } & \text { menu } \\
\text { aplikasi. } & \end{array}$ & Berhasil \\
\hline 10. & Keluar aplikasi & $\begin{array}{l}\text { Pengguna } \\
\text { berada pada } \\
\text { halaman menu. }\end{array}$ & $\begin{array}{l}\text { Sistem } \\
\text { menampilkan } \\
\text { halaman keluar, jika } \\
\text { dipilih ya maka } \\
\text { aplikasi berhenti dan } \\
\text { keluar, jika tidak } \\
\text { maka kembali ke } \\
\text { halaman menu. }\end{array}$ & Berhasil \\
\hline 11. & Tombol putar & $\begin{array}{l}\text { Pengguna } \\
\text { berada pada } \\
\text { halaman gambar } \\
\text { 3D dan berhasil } \\
\text { memindai } \\
\text { penanda }\end{array}$ & 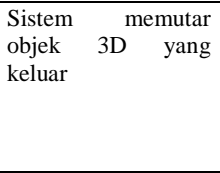 & Berhasil \\
\hline 12. & $\begin{array}{l}\text { Scrollbar } \\
\text { perbesar }\end{array}$ & $\begin{array}{l}\text { Pengguna } \\
\text { berada pada } \\
\text { halaman gambar } \\
\text { 3D dan berhasil } \\
\text { memindai } \\
\text { penanda }\end{array}$ & \begin{tabular}{l}
\multicolumn{3}{l}{ Sistem memperbesar } \\
objek 3D yang \\
keluar
\end{tabular} & Berhasil \\
\hline 13. & Dialogbox & $\begin{array}{l}\text { Pengguna } \\
\text { berada pada } \\
\text { halaman gambar } \\
\text { 3D dan berhasil } \\
\text { memindai } \\
\text { penanda }\end{array}$ & $\begin{array}{l}\text { Keluar dialogbox } \\
\text { sesuai tombol 3D } \\
\text { yang ditekan }\end{array}$ & Berhasil \\
\hline 14. & Tombol angka & $\begin{array}{l}\text { Pengguna } \\
\text { berada pada } \\
\text { halaman animasi } \\
\text { 3D angka dan } \\
\text { berhasil } \\
\text { memindai } \\
\text { penanda } \\
\end{array}$ & $\begin{array}{l}\text { Keluar suara dan } \\
\text { animasi 3D angka } \\
\text { sesuai tombol yang } \\
\text { ditekan }\end{array}$ & Berhasil \\
\hline 15. & Tombol warna & $\begin{array}{l}\text { Pengguna } \\
\text { berada pada } \\
\text { halaman animasi } \\
\text { 3D warna dan } \\
\text { berhasil } \\
\text { memindai } \\
\text { penanda } \\
\end{array}$ & $\begin{array}{l}\text { Keluar suara dan } \\
\text { animasi 3D warna } \\
\text { sesuai tombol yang } \\
\text { ditekan }\end{array}$ & Berhasil \\
\hline 16. & gambar & Pengguna & Keluar suara sesuai & Berhasil \\
\hline
\end{tabular}

\begin{tabular}{|l|l|l|l|l|}
\hline 3D & $\begin{array}{l}\text { berada pada } \\
\text { halaman gambar } \\
\text { 3D dan berhasil } \\
\text { memindai dai dan } \\
\text { penanda dang } \\
\text { telah keluar } \\
\text { dialogbox }\end{array}$ & & \\
ditekan & & & \\
\end{tabular}

\section{Pengujian Keberhasilan Deteksi}

Pengujian keberhasilan deteksi merupakan pengujian mengenai halaman utama aplikasi. Halaman utama aplikasi memiliki fungsi menghidupkan kamera dan membaca objek penanda dari buku untuk memunculkan gambar 3D, animasi 3D maupun video. Variabel yang digunakan adalah jarak, sudut serta halangan pada gambar penanda. Indikator keberhasilan adalah munculnya gambar 3D, animasi 3D ataupun video saat kamera diarahkan pada gambar penanda dalam buku. Jumlah gambar penanda dalam aplikasi ini adalah 20, sehingga pengujian dilakukan disetiap penanda. Tabel 2 menunjukkan pengujian jarak dan sudut dalam mendeteksi penanda dengan kondisi cahaya tidak menghalangi gambar penanda pada kamera.

\begin{tabular}{|c|c|c|c|c|c|}
\hline \multirow{2}{*}{ Sudut } & \multirow{2}{*}{$\begin{array}{l}\text { Jarak } \\
(\mathrm{Cm})\end{array}$} & \multicolumn{2}{|c|}{ Keterangan } & \multirow{2}{*}{ Persentase } & \multirow{2}{*}{$\begin{array}{c}\text { Hasil } \\
\text { Persentase }\end{array}$} \\
\hline & & Berhasil & Gagal & & \\
\hline \multirow{5}{*}{$0^{\circ}$} & 0 & 0 & 20 & $\overline{20} \times 100 \%$ & $0 \%$ \\
\hline & $15-20$ & 20 & 0 & $\frac{20}{20} \times 100 \%$ & $100 \%$ \\
\hline & $25-30$ & 20 & 0 & $\frac{20}{20} \times 100 \%$ & $100 \%$ \\
\hline & $40-45$ & 20 & 0 & $\frac{20}{20} \times 100 \%$ & $100 \%$ \\
\hline & $55-60$ & 20 & 0 & $\frac{20}{20} \times 100 \%$ & $100 \%$ \\
\hline \multirow{5}{*}{$30^{\circ}$} & 0 & 0 & 20 & $\overline{20} \times 100 \%$ & $0 \%$ \\
\hline & $15-20$ & 20 & 0 & $\frac{20}{20} \times 100 \%$ & $100 \%$ \\
\hline & $25-30$ & 20 & 0 & $\frac{20}{20} \times 100 \%$ & $100 \%$ \\
\hline & $40-45$ & 20 & 0 & $\frac{20}{20} \times 100 \%$ & $100 \%$ \\
\hline & $55-60$ & 20 & 0 & $\frac{20}{20} \times 100 \%$ & $100 \%$ \\
\hline \multirow{5}{*}{$60^{\circ}$} & 0 & 0 & 20 & $\frac{-10}{20} \times 100 \%$ & $0 \%$ \\
\hline & $15-20$ & 0 & 20 & $\overline{20} \times 100 \%$ & $0 \%$ \\
\hline & $25-30$ & 0 & 20 & $\overline{20} \times 100 \%$ & $0 \%$ \\
\hline & $40-45$ & 0 & 20 & $\overline{20} \times 100 \%$ & $0 \%$ \\
\hline & $55-60$ & 0 & 20 & $\overline{20} \times 100 \%$ & $0 \%$ \\
\hline \multirow{5}{*}{$90^{\circ}$} & 0 & 0 & 20 & $\frac{-10}{20} \times 100 \%$ & $0 \%$ \\
\hline & $15-20$ & 0 & 20 & $\overline{20} \times 100 \%$ & $0 \%$ \\
\hline & $25-30$ & 0 & 20 & $\frac{-10}{20} \times 100 \%$ & $0 \%$ \\
\hline & $40-45$ & 0 & 20 & $\frac{-}{20} \times 100 \%$ & $0 \%$ \\
\hline & $55-60$ & 0 & 20 & $\overline{20} \times 100 \%$ & $0 \%$ \\
\hline
\end{tabular}

Pengujian halangan dilakukan pada jarak $25-30 \mathrm{~cm}$ tanpa kemiringan sudut. Jarak tersebut dipilih karena jarak $25-30 \mathrm{~cm}$ merupakan salah satu jarak ideal yang memiliki persentase keberhasilan $100 \%$. Halangan yang dimaksud adalah dengan menutupi sebagian penanda/marker dengan penghalang kertas. Tabel 3 
menunjukkan hasil pengujian halangan pada gambar penanda.

Tabel 3 Pengujian halangan pada penanda.

\begin{tabular}{|c|c|c|c|c|}
\hline \multirow{2}{*}{$\begin{array}{c}\text { Jumlah } \\
\text { Halangan. }\end{array}$} & \multicolumn{2}{|c|}{ Keterangan } & \multirow{2}{*}{ Persentase } & $\begin{array}{c}\text { Hasil } \\
\text { Persentase }\end{array}$ \\
\cline { 2 - 3 } & Berhasil & Gagal & & $100 \%$ \\
\hline $0 \%$ & 20 & 0 & $\frac{20}{20} \times 100 \%$ & $100 \%$ \\
\hline $50 \%$ & 20 & 0 & $\frac{20}{20} \times 100 \%$ & $0 \%$ \\
\hline $75 \%$ & 0 & 20 & $\overline{20} \times 100 \%$ & $0 \%$ \\
\hline $100 \%$ & 0 & 20 & $\overline{20} \times 100 \%$ & $0 \%$ \\
\hline
\end{tabular}

\section{Penutup}

\subsection{Kesimpulan}

Berdasarkan hasil analisis dan pengujian pada aplikasi Bahasa Inggris AR, maka dapat diambil kesimpulan sebagai berikut :

1. Penggunaan aplikasi Bahasa Inggris AR dapat digunakan dengan memadukan buku pembelajaran bahasa inggris dengan augmented reality sebagai tempat meletakkan penanda agar bahasa inggris dapat dinikmati dengan nuansa augmented reality, yaitu memadukan realitas dan objek virtual secara interaktif dengan mempertimbangkan beberapa aspek yaitu sudut, jarak dan kenampakkan penanda.

2. Berdasarkan pengujian keberhasilan deteksi, ada beberapa sudut serta jarak yang perlu diperhatikan. Sudut $0^{0}$ dan $30^{\circ}$ dengan rentang jarak antara $15-60 \mathrm{~cm}$ dengan kondisi cahaya tidak menutupi penanda merupakan sudut dan jarak dengan tingkat keberhasilan $100 \%$ dalam mendeteksi pananda. Sedangkan sudut $60^{\circ}$ dan $90^{\circ}$ merupakan sudut dimana tingkat keberhasilan dalam mendeteksi penanda $0 \%$, yang artinya sudut ini tidak memungkinkan aplikasi untuk mendeteksi penanda.

3. Berdasarkan pengujian halangan, aplikasi masih mampu mendeteksi penanda saat kondisi penanda terhalang dari $0 \%$ - 25\%. Sementara saat penanda terhalang antara 50\% - 100\%, aplikasi tidak mampu mendeteksi penanda.

4. Berdasarkan pengujian fungsionalitas, aplikasi berjalan dengan baik dengan semua halaman dan tombol dapat digunakan dan menampilkan tanggapan sesuai dengan yang dituju.

\subsection{Saran}

Pada aplikasi Bahasa Inggris AR ini, masih terdapat beberapa hal yang memungkinkan untuk dikembangkan selanjutnya. Beberapa saran untuk pengembangan aplikasi ini selanjutnya yaitu:

1. Perlu adanya penambahan kosa kata yang lebih banyak lagi sehingga pengguna lebih banyak lagi dalam belajar kosa kata bahasa inggris.

2. Perlu dikembangkannya antarmuka yang lebih menarik dengan menerapkan efek transisi pada setiap pergantian halaman dan tidak memerlukan waktu lama dalam pergantian tersebut, serta perlu adanya pengembangan antarmuka tombol yang lebih menarik.

\section{DAFTAR PUSTAKA}

[1] Endah, Andrea Tyas Asri Jati, Desain Interior Toko Buku Dan Kafe "Magnet Zone” Dengan Langgam Modern Retro, Tesis S-2, Institut Teknologi Surabaya, Surabaya.

[2] Martono, Kurniawan Teguh, and Kridalukmana, Rinta, Mobile Augmented Reality Jurusan Sistem Komputer Universitas Diponegoro Berbasis Android (MARSISKOM), JURNAL SISTEM KOMPUTER, Vol. 4 (No.1). ISSN 2087-4685 e-ISSN 2252-3456, 2014.

[3] Martono, Kurniawan Teguh, Augmented Reality Sebagai Metafora Baru dalam Teknologi Interaksi Manusia dan Komputer, JURNAL SISTEM KOMPUTER, Vol.1 (No.2). ISSN 2087-4685, 2011.

[4] Mulyani NS., S., Peranan Metode Pengembangan System Development Life Cycle (SDLC) Terhadap Kualitas Sistem Informasi, Univesitas Pandjadjaran, bandung, 2009.

[5] Nugraha, Iwan Setya and Satoto, Kodrat Iman and Martono, Kurniawan Teguh, Pemanfaatan Augmented Reality Untuk Pembelajaran Pengenalan Alat Musik Piano. Skripsi S-1, Universitas Diponegoro, Semarang, 2014.

[6] Prasetyo BA., Arief, Rancang Bangun Media Promosi Tempat Wisata Kabupaten Temanggung Berbasis Multimedia, Universitas Dian Nuswantoro, Semarang.

[7] Rifqi Andikasani, Muhammad and Awaluddin, Moehammad and Suprayogi, Andri and Darmo Yuwono, Bambang, Aplikasi persebaran Objek Wisata Di Kota Semarang Berbasis Mobile GIS memanfaatkan Smartphone Android, Tesis S-2, Universitas Diponegoro, Semarang, 2014.

[8] Setyawan, Dwi Aris, Aplikasi Mutimedia Pembelajaran Bahasa Inggris Bagi Anak-Anak, Universitas Sebelas Maret, Surakarta, 2007.

[9] Young-geun, K., and K. Won-jung, Implementation of Augmented Reality System for Smartphone Advertisements. Department of Computer Science Sunchon National University, 2014. 